\title{
What causes cryptogenic fibrosing alveolitis? A case-control study of environmental exposure to dust
}

\author{
Jonathan Scott, Ian Johnston, John Britton
}

\begin{abstract}
Objective-To investigate the role of occupational and domestic exposure to dust in the aetiology of cryptogenic fibrosing alveolitis.

Design-Matched case-control study.

Subjects - 40 Patients with cryptogenic fibrosing alveolitis and 106 community controls matched for age and sex who responded to a questionnaire.

Main outcome measure-Responses to self administered questionnaire asking about lifetime exposure to dust, animals, and smoke at home and at work.

Results - The patients with cryptogenic fibrosing alveolitis were more likely to report occupational exposure to metal dust (matched odds ratio 10.97 (95\% confidence interval 2.30 to 52.4 ), $\mathrm{p}<0.001$ ) or wood dust $(2.94(0.87$ to 9.90$), p=0.08)$, to have worked with cattle $(10.89(1.24$ to 96.0$), p=0.01)$, and to have lived in a house heated by a wood fire (12.55 $(1.04$ to 114$), p=0.009)$. A history of smoking and social class based on occupation were not significantly related to disease state.

Conclusion-Environmental exposure to dust may be an important factor in the aetiology of cryptogenic fibrosing alveolitis.
\end{abstract}

\section{Introduction}

Cryptogenic fibrosing alveolitis has a prevalence of roughly five cases per $100000,{ }^{12}$ and patients survive for about four to five years after it is diagnosed. ${ }^{34} \mathrm{It}$ generally develops between the ages of 40 and 70 but may occur in childhood. ${ }^{56}$ Mortality from the disease is increasing in England and Wales, ${ }^{7}$ with over 600 deaths each year.

The cause or causes of cryptogenic fibrosing alveolitis and the explanation for the increasing mortality are unknown. In the accompanying paper we described small but significant differences in mortality from the disease among standard regions of England and Wales. ${ }^{7}$ This suggests that environmental exposure to some agent(s) may have a role in the aetiology of the disease, and as mortality is highest in the traditionally industrial areas of England and Wales some of this exposure may be related to industrial occupations.? We tested the hypothesis that environmental exposure to dust has a role in the aetiology of cryptogenic fibrosing alveolitis by comparing lifetime occupational and domestic exposure to various dusts in all patients with the disease known to the Nottingham hospitals and a series of community controls matched for age and sex.

Respiratory Medicine Unit, NG5 1PB

John Britton, MD, lecturer

Correspondence to:

Dr Johnston.

BrMed F 1990;301:1015-7
We reviewed the case notes of patients on a register of all patients with cryptogenic fibrosing alveolitis seen by respiratory physicians or tested in the pulmonary function laboratories in Nottingham in the two years before the study. The disease was confirmed if the patient had documented inspiratory basal crackles, bilateral interstitial shadowing in chest $x$ ray films, restrictive pulmonary function, and a noted absence of appreciable exposure to known occupational or other fibrogenic agents in the past. Up to four controls matched for age and sex were obtained for each index patient. These controls were drawn from the list of the index patient's general practitioner (held by the family practitioner committee) and were selected randomly if more than four suitable subjects were available; if four controls of the same age were not listed with the general practitioner the age matching was widened to within five years.

Permission to enter an index patient and the matched controls into the study was requested from the general practitioner, and on receipt of permission a questionnaire was posted to the subject's home. The questionnaire included questions on previous areas of residence, past and present occupations and their duration, the duration of exposure to occupational dusts and their type, exposure to animals at work or at home, types of heating in current and previous housing, smoking history, and symptoms of allergy. Ethical permission for the study was granted by Nottingham City Hospital's ethics committee.

The data obtained with the questionnaire were coded and entered into the mainframe computer system at Nottingham University and were analysed descriptively with the Statistical Package for the Social Sciences-(SPSS-X) ${ }^{8}$ Occupations were coded by using the classification of occupations of the Office of Population Censuses and Surveys and were categorised prospectively as dirty or clean according to whether the job description in this classification implied direct exposure to atmospheric dust (table I). ${ }^{9}$ Matched casecontrol analysis of occupational and domestic exposure to dust, cigarette smoking, and other variables of primary interest was by conditional logistic regression with the statistical package EGRET $^{10}$ on a microcomputer.

\section{Results}

We obtained the general practitioner's permission to contact 43 index patients and their controls. Four controls were found for 39 of the index patients and at least one control for each of the four other patients. Forty index patients ( $87 \%$ of the 46 originally identified) and 106 controls ( $60 \%$ of the original sample) returned a completed questionnaire. The proportions of men and women among all the index patients and controls identified and those who returned the questionnaire were similar, as were their mean ages (table II).

Occupational exposure to dust of any sort at any time was reported by 27 index patients and 47 controls. The 
TABLE I - Fobs classified as dirty and their ICD codes

\begin{tabular}{ll}
\hline Job & \multicolumn{1}{c}{ ICD codes } \\
\hline Textile worker & 087 \\
Furnaceman, smith & 096,109 \\
Materials processor (textiles, tobacco) & 098 \\
Woodworker, sawyer & 105,106 \\
Craftsman, labourer & 107.1 \\
Metal worker, fitter, or machinist & $110,113,117,126$ \\
Machine (for example, lathe) operator & 097,112 \\
Welder or galvaniser & 128,131 \\
Builder, construction worker, or labourer & $140,141,142,160$ \\
Miner, quarryman & 145,146 \\
\hline
\end{tabular}

TABLE II - Distributions of age and sex among all index patients and controls identified and all respondents to questionnaire

\begin{tabular}{|c|c|c|c|c|c|c|}
\hline & \multirow[b]{2}{*}{ No } & \multicolumn{2}{|c|}{ Men } & \multicolumn{2}{|c|}{ Women } & \multirow{2}{*}{$\begin{array}{l}\text { Overall mear } \\
\text { (SD) age } \\
\text { (years) }\end{array}$} \\
\hline & & No $(\%)$ & $\begin{array}{l}\text { Mean }(\mathrm{SD}) \\
\text { age (years) }\end{array}$ & No $(\%)$ & $\begin{array}{l}\text { Mean }(S D) \\
\text { age (years) }\end{array}$ & \\
\hline \multicolumn{7}{|l|}{ Original sample: } \\
\hline Index patients & 46 & $35(76)$ & $66 \cdot 7(9 \cdot 2)$ & $11(24)$ & $68 \cdot 0(9 \cdot 1)$ & $66 \cdot 9(9 \cdot 1)$ \\
\hline Controls & 177 & $133(75)$ & $65 \cdot 7(8 \cdot 3)$ & $44(25)$ & $68 \cdot 0(8 \cdot 7)$ & $66 \cdot 3(8 \cdot 5)$ \\
\hline \multicolumn{7}{|l|}{ Respondents: } \\
\hline Index patients & 40 & $30(75)$ & $66 \cdot 8(8 \cdot 9)$ & $10(25)$ & $67 \cdot 6(9 \cdot 4)$ & $66.9(8.9)$ \\
\hline Controls & 106 & $80(75)$ & $66 \cdot 7(8 \cdot 8)$ & $26(25)$ & $67 \cdot 1(9 \cdot 2)$ & $66 \cdot 8(8 \cdot 4)$ \\
\hline
\end{tabular}

TABLE III-Exposure to various dusts in index patients and controls and matched odds ratios for disease

\begin{tabular}{lcccc}
\hline & $\begin{array}{c}\text { No of index } \\
\text { patients }\end{array}$ & $\begin{array}{c}\text { No of } \\
\text { controls }\end{array}$ & $\begin{array}{c}\text { Matched odds ratio } \\
(95 \% \text { confidence } \\
\text { interval })\end{array}$ & p Value \\
\hline Any dust & 27 & 47 & $1.32(0.84$ to 2.04$)$ & 0.19 \\
Metal & 6 & 2 & $10.97(2.30$ to 52.4$)$ & $<0.001$ \\
Wood & 6 & 5 & $2.94(0.87$ to 9.90$)$ & 0.08 \\
Asbestos & 4 & 9 & $1.46(0.42$ to 5.09$)$ & 0.56 \\
Coal & 8 & 22 & $1.23(0.44$ to 3.44$)$ & 0.70 \\
Stone or sand & 6 & 16 & $1.59(0.52$ to 4.79$)$ & 0.42 \\
Tobacco & 5 & 7 & $1.11(0.13$ to 1.40$)$ & 0.29 \\
Fabric & 3 & 10 & $0.90(0.24$ to 3.44$)$ & 0.88 \\
Cows & 5 & 3 & $10.89(1.24$ to 96.0$)$ & 0.01 \\
Wood fires & 4 & 1 & $12.55(1.40$ to 114.00$)$ & 0.009 \\
\hline
\end{tabular}

dusts reported were metal, wood, coal, sand or stone, fabric, and tobacco dusts. Four index patients also reported occupational exposure to asbestos; in two of these cases the exposure had been recorded in the clinical notes and considered to be unimportant, and in two the exposure had not been recorded. The odds of disease given exposure to any of these dusts were not significantly increased (matched odds ratio $1 \cdot 32(95 \%$ confidence interval 0.85 to $2 \cdot 04$ ), $\mathrm{p}=0.19$ ), but in relation to exposure to specific dusts more of the index patients had been exposed to metal dust $(10.97$ ( 2.30 to $52.4), \mathrm{p}<0.001)$ and wood dust $(2.94(0.87$ to 9.90$)$, though the effect of wood dust did not quite reach significance $(p=0.08)$. Exposure to coal, asbestos, sand or stone, tobacco, or fabric dust did not differ signifcantly between the index patients and controls (table III). Index patients were more likely than controls, however, to have had occupations classified as dirty $(3 \cdot 09,1 \cdot 23$ to $7 \cdot 89, \mathrm{p}<0 \cdot 01)$, even after adjustment for exposure to wood and metal dusts (adjusted odds ratio $2 \cdot 15(0 \cdot 78$ to $5 \cdot 95), \mathrm{p}=0 \cdot 14)$.

Index patients were more likely than controls to have worked with cattle (odds ratio $10.89(1.24$ to $96 \cdot 0)$, $\mathrm{p}=0.01$ ) and to have lived in a house heated by a wood fire $(12.55(1.40$ to 114$), \mathrm{p}<0.01)$. There was no association between disease state and a history of having ever smoked (odds ratio $0.93(0.37$ to 2.35 ), $\mathrm{p}=0.88$ ), duration of residence in any of the standard regions of the United Kingdom, social class based on occupation (manual or non-manual), age at leaving school, exposure to pets and animals other than cows, passive smoking, or domestic heating other than wood fires. Exposure to factors significantly associated with cryptogenic fibrosing alveolitis had always predated the clinical onset of the disease, in most patients by at least 10 years.

Allergic symptoms, defined as cough, wheeze, tight- ness of the chest, shortness of breath, runny nose, or itchy eyes, were reported significantly more commonly by the index patients in association with exposure to household dust $(2.60(1.25$ to 5.41$), p=0.001)$, and tree, grass, or flower pollen $(2.30$ (1.09 to 4.85$)$, $\mathrm{p}=0 \cdot 03$ ).

\section{Discussion}

In this study we identified patients with cryptogenic fibrosing alveolitis by applying clinical criteria similar to those used previously ${ }^{11}$ and did not use histological criteria because lung biopsy is not widely used to investigate the disease in the United Kingdom. ${ }^{12}$ We selected individually matched controls as the simplest and most efficient means of controlling for confounding by age, sex, and referral bias by the general practitioner.

Our identification of 46 patients with the disease among a local population of roughly 750000 suggests a prevalence of about six cases per 100000 , which is slightly higher than previous estimates. ${ }^{12}$ The higher proportion of men among our patients than in previous studies $^{3413}$ does not necessarily reflect sampling bias because previous reports have tended to be on selected patients from tertiary referral centres. A higher prevalence in men is also suggested by the fact that mortality from the disease in men is roughly double that in women.? We were unable to determine, however, whether the effect of male sex is independent of occupational exposure to agents, because of the individual matching of cases and controls for sex.

We used a self administered questionnaire to collect information on exposure to dust and attempted to limit recall bias by keeping the patients and controls blinded to the hypothesis being tested. Some bias in recalling occupation is, however, inevitable because our patients had already had to provide occupational histories in the course of their clinical assessment. We were unable to validate the questionnaire responses on exposure to dust against any external standard, but responses to questions on exposure to animals and dust and on lifetime occupations were internally consistent. The data recorded with the questionnaire can therefore be considered to be reasonably valid.

The agents to which subjects reported occupational exposure in the questionnaire included a wide variety of dusts, particularly coal, sand or stone, fabric, tobacco, and asbestos dusts. Not all of these, however, would be expected to increase the risk of cryptogenic fibrosing alveolitis because some are recognised causes of other diagnostic categories of fibrotic lung disease. For example, clinically important exposure to asbestos in a patient with fibrosis of the lungs should lead to a diagnosis of asbestosis rather than cryptogenic fibrosing alveolitis and exposure to coal, sand, or stone dust may lead to a diagnosis of pneumoconiosis. In the event none of these exposures was associated with a significantly increased risk of cryptogenic fibrosing alveolitis. Whether a diagnosis of cryptogenic fibrosing alveolitis is justifiable when the patient has a history of exposure to asbestos, however minor, is unresolved; excluding the four patients with any exposure to asbestos from the analysis, however, did not substantially alter the results in relation to exposure to other dusts significantly associated with disease.

We found that exposure to metal dust was significantly increased in the patients. We also found a strong though non-significant association between cryptogenic fibrosing alveolitis and exposure to wood dust and a more general association with occupations classified as dirty. The patients were also more likely than the controls to have worked with cattle or to have been exposed to wood fires at home. Collectively these results support our hypothesis that environmental 
dusts have a role in the aetiology of cryptogenic fibrosing alveolitis. Several metal dusts have been implicated as causes of pulmonary fibrosis, ${ }^{14}$ but whether in our patients metal and wood dusts were true fibrotic agents or markers of exposure to other fibrogens is not clear. For example, workers exposed to metal dust are often also exposed to grinding or lubricating materials, and joiners exposed to wood dust may also work with insulation or roofing materials containing asbestos.. In relation to exposure to cattle, cryptogenic fibrosing alveolitis in a dairy worker has previously been attributed to occupational exposure to hydrogen peroxide. ${ }^{15}$ Clearly, the extent of confounding by exposure to other agents needs to be explored, but the necessary detail is not available in the present study. Our finding that patients with cryptogenic fibrosing alveolitis had had a higher exposure to domestic wood fires adds support to a suggestion that wood smoke may be a cause of the disease. ${ }^{16}$ Cigarette smoke, however, had no appreciable effect in the present study despite an apparent protective effect against lung fibrosis due to extrinsic allergic alveolitis or sarcoidosis. ${ }^{17} 18$

The relevance of the increased reporting of allergic symptoms by our patients is not clear as shortness of breath on exposure to allergens may be a non-specific symptom and recall bias may also have contributed. Further investigation of this is therefore indicated. Future studies should also investigate whether disease associated with inhalation of dust differs in terms of histological findings or clinical progress from the classic rapidly progressing form of the disease as cryptogenic fibrosing alveolitis might be a stereotyped end organ response to many different aetiological factors. The present evidence associating the disease with potentially avoidable exposure to environmental agents, however, raises the possibility that it may at least to some extent be preventable.
We thank Dr Jim Pearson for his advice on computing and statistics, Mrs Mary Stevenson for entering and verifying the data, and Mrs Bernadette Maughan and others of the family practitioner committee for selecting the controls.

Copies of the questionnaire are available on request.

1 Crystal RG, Bitterman PB, Rennard SI, Hance AJ, Keogh BA. Interstitial lung diseases of unknown cause. Part I. N Engl f Med 1984;310:154-63.

2 Grant IWB. Cryptogenic fibrosing alveolitis. In: Weatherall DJ, Ledingham JGG, Warrell DA, eds. Oxford textbook of medicine. 2nd ed. Oxford: Oxford University Press: 1987:15.123-5.

3 Stack HR, Choo-Kang YFJ, Heard BE. The prognosis of cryptogenic fibrosing alveolitis. Thorax 1972;27:535-42.

4 Turner-Warwick $M$, Burrows B, Johnson A. Cryptogenic fibrosing alveolitis: clinical features and their influence on survival. Thorax 1980;35:171-80.

5 Crystal RG, Fulmer JD, Roberts WC, Moss ML, Line BR, Reynolds HY. Idiopathic pulmonary fibrosis: clinical, histologic, radiographic, physiologic, scintographic, cytologic and biochemical aspects. Ann Intern Med 1976;85:769-88.

6 Chetty A, Bhuvan UN, Mitra DK, Roy S, Deorati A. Cryptogenic fibrosing alveolitis in children. Ann Allergy 1987;58:336-40.

7 Johnston IDA, Britton JR, Kinnear WJM, Logan RFA. Rising mortality from cryptogenic fibrosing alveolitis. Br Med f 1990;301:1017-21.

8 SPSS Inc. Statistical package for the social sciences-SPSS-X: user's guide. $2 \mathrm{nd}$ ed. New York: McGraw Hill, 1986.

9 Office of Population Censuses and Surveys. Classification of occupations 1980. London: HMSO, 1980.

10 Anonymous. EGRET reference manual. First draft. Seattle: Statistics and Epidemiology Research Corporation and Cytel Software Corporation, 1990 Robinson BWS, Rose AH. Pulmonary gamma-interferon production in patients with fibrosing alveolitis. Thorax 1990;45:105-8

12 Bleasdale C, Johnston IDA, Kara S, Woodcock AA, Evans CC, Hind CRK. Management of patients with cryptogenic fibrosing alveolitis in the 1980s: experience in three regions. Thorax 1989;44:346P.

13 Liebow AA, Steer A, Billingsley JG. Desquamative interstitial pneumonia. Am f Med 1965;39:369-404

14 Morgan WKC, Seaton A. Occupational lung diseases. London: W B Saunders, 1984.

15 Kaelin RM, Kapanci Y, Tschopp JM. Diffuse interstitial lung disease associated with hydrogen peroxide inhalation in a dairy worker. Am Rev Respir Dis 1988;137:1233-5.

16 Ramage JE, Roggli VL, Bell DY, Piantadosi CA. Interstitial lung disease and domestic wood burning. Am Rev Respir Dis 1988;137:1229-32

17 Depierre A, Dalphin JC, Pernet D, Dubiez A, Faucompre C, Breton JL. Epidemiological study of farmer's lung in five districts of the French Daubs province. Thorax 1988;43:429-35.

18 Valeyre D, Soler P, Clarici C, et al. Smoking and pulmonary sarcoidosis: effect of cigarette smoking on prevalence, clinical manifestations, alveolitis and evolution of the disease. Thorax 1988;43:516-24.

(Accepted 15 August 1990)
University Hospital, Nottingham NG7 2UH Ian Johnston, $\mathrm{MD}$, consultant physician

William Kinnear, MD, senior registrar

Respiratory Medicine Unit, City Hospital, Nottingham NG5 1PB

John Britton, MD, lecturer

Department of Community Medicine and

Epidemiology, Queen's

Medical Centre,

Nottingham NG7 2UH

Richard Logan, FRCPED, senior lecturer

Correspondence to: Dr Johnston.

BrMed f 1990;301:1017-21

\title{
Rising mortality from cryptogenic fibrosing alveolitis
}

\author{
Ian Johnston, John Britton, William Kinnear, Richard Logan
}

Abstract
Objective-To determine the pattern of mortality ascribed to cryptogenic fibrosing alveolitis and to identify factors that might be important in the aetiology of the disease; and to assess the validity of death certification of the disease.

Design - A retrospective examination of mortality ascribed to cryptogenic fibrosing alveolitis in England and Wales between 1979 and 1988 with analysis, by multiple logistic regression, of independent effects of age, sex, region of residence, and social class as indicated by occupation on data for 1979-87; also a retrospective review of hospital records of patients certified as having died of cryptogenic fibrosing alveolitis in Nottingham and of the certified cause of death of patients known to have had the disease.

Main outcome measures - Time trends in mortality nationally; effects on mortality of age, sex, and region of residence; validity of death certification in Nottingham.

Results - The annual number of deaths ascribed to cryptogenic fibrosing alveolitis doubled from 336 in 1979 to 702 in 1988, the increase occurring mainly at ages over 65 . Mortality standardised for age for both sexes likewise increased steadily over the period. Deaths due to cryptogenic fibrosing alveolitis were commoner in men (odds ratio $2 \cdot 24,95 \%$ confidence interval $2 \cdot 11$ to 2.33 ) and increased substantially with age, being $7.84(7.24$ to 8.49$)$ times higher in subjects aged $\geqslant 75$ than those aged 45-64. Odds ratios of death due to cryptogenic fibrosing alveolitis adjusted for age and sex were increased in the traditionally industrialised central areas of England and Wales $(p<0.02$, maximum odds ratio between regions 1.25 ), but no significant increase in odds of death was found for manual occupations. Of 23 people whose deaths were registered in Nottingham as having been due to cryptogenic fibrosing alveolitis, 19 were ascertained from clinical records to have had the disease. Only 17 of 45 patients known to have had cryptogenic fibrosing alveolitis in life were recorded as having died from the disease.

Conclusions-The diagnostic accuracy of death certification of cryptogenic fibrosing alveolitis is high, but the number of deaths recorded as being due to the disease may underestimate the number of patients dying with the disease by up to half. Mortality due to the disease is increasing, and the male predominance and regional differences in mortality suggest that environmental factors are important in its aetiology.

\section{Introduction}

The aetiology of cryptogenic (idiopathic) fibrosing alveolitis is unknown, and the mean life expectancy of a patient after presentation with the disease is only four 